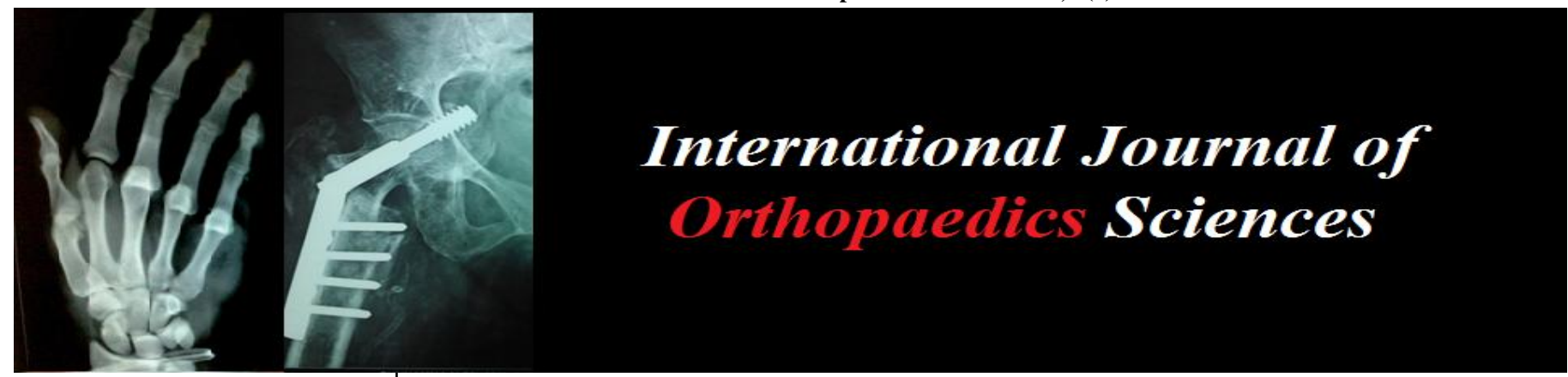

ISSN: $2395-1958$

IJOS 2017; 3(4): 250-255

(C) 2017 IJOS

www.orthopaper.com

Received: 10-08-2017

Accepted: 14-09-2017

Reda H EIKady MD

Orthopedic Department, Zagazig

University, Egypt

Nagy Fuda MD

Orthopedic Department, Zagazig

University, Egypt

\section{Treatment of type III Acromioclavicular dislocation with open reduction and percutaneous $\mathrm{K}$-wire fixation}

\author{
Reda H ElKady and Nagy Fuda
}

DOI: https://doi.org/10.22271/ortho.2017.v3.i4d.35

\section{Abstract}

Background: The direct force acting on the shoulder from the lateral side with the arm in an adducted position is the main mechanism of injury in the vast majority of traumatic dislocations of the acromioclavicular joint.

Patients and method: Fourteen patients with an acromioclavicular separation (Rockwood type III) were surgically treated with open reduction, repair of the capsule, and percutaneous $2 \mathrm{~K}$-wires fixation under image intensifier. There were 10 men and 4 women with a mean age of 37 years from 23 to 60 ). The surgery was done 10.2 days average after trauma (range 3-21 days).

Results: The follow-up period ranged from 8 months to 30 months (Average $18 \mathrm{~m}$ ). According to Constant score seven patients had excellent score, five good, two fair, and no poor results were obtained. Complications were two migrated K-wires five weeks postoperative were removed without influence on the final result. Superficial wound infections occurred in three cases and needed no further surgical treatment, only dressing and oral antibiotic for two weeks. Shoulder stiffness was mild in two cases and did not impair in the patient daily activities. We had no deep infections or nerve palsies.

Conclusion: Open reduction, repair of the capsule, and percutaneous transfixing $2 \mathrm{~K}$-wires is a valid and good method for treatment of type III Rockwood type acromioclavicular dislocation with little rate of subluxation, joint stiffness, or ligament ossification.

Keywords: Treatment, Acromioclavicular dislocation, K-wire fixation

\section{Introduction}

The vast majority of traumatic dislocations of the acromioclavicular joint occur either during sports or other daily activities ${ }^{[1-3]}$. Most frequently the mechanism of injury is a force acting on the shoulder from the lateral side with the arm in an adducted position ${ }^{[4]}$. On the basis of the direction and amount of clavicular displacement, Rockwood introduced a classification of acromioclavicular joint (ACJ) dislocations from grade I to VI ${ }^{[5]}$. It is mostly accepted that grade I and II lesions are benign and can be treated conservatively ${ }^{[6,7]}$. There is also wide consensus that type IV to VI injuries should be treated operatively. Nevertheless, for type III ACJ injuries the discussion concerning conservative or operative treatment is still controversial $^{[2-4]}$.

There is a great variety of operative treatment options: Open reduction of the acromioclavicular joint and reconstruction of the ligaments without any further fixation, the different fixation methods can be grouped into transarticular acromioclavicular techniques, coracoclavicular fixation techniques, and secondary interventions like excision of the lateral clavicle or muscle transfer procedures. Transarticular fixation by K-wires, screws, or tensionband techniques is commonly used. Several authors have described a high rate of complications, such as bending, breakage or migration of the pins ${ }^{[8,9]}$. Stabilization by the use of hinged plates, definitely improves stability of the repair, and allows early mobilization ${ }^{[10-}$ ${ }^{12}$. On the other hand, it represents an extensive procedure with the necessity of an equivalent access for an eventual implant removal.

Additional repair of the acromioclavicular ligaments is optional, but not recommended in all cases. The coracoclavicular ligaments are normally not addressed during these procedures ${ }^{[13]}$. Extraarticular fixation techniques such as the Bosworth screw, coracoclavicular loop wire, Dacron loop, or polyethylene augmentation devices represent an indirect fixation method of the joint ${ }^{[14-16]}$.

\section{Correspondence}

Reda H ElKady MD

Orthopedic Department, Zagazig

University, Egypt 
The aim of this prospective study is to report the functional outcome of type III separations managed by open reduction, capsule repair, and percutaneous acromioclavicular fixation with two k-wires.

During the period from January 2005 and October 2009, 14 patients with an acromioclavicular separation type III by Rockwood ${ }^{[5]}$ were surgically treated. There were 10 men and 4 women with a mean age of 37 years from 23 to 60). The surgery was done at an average of 10.2 days after trauma (range 3-21 days). The cause of trauma in eight cases was falling during manual work, domestic falls in two, car accident in two, and sports injury in two cases. Initial radiographic evaluations (included an AP view, a scapular yview of the injured shoulder and a weighted AP stress view of both acromioclavicular joints on a single wide film). All patients were treated with open reduction, capsule repair, and percutaneous $2 \mathrm{~K}$-wires only under image intensifier.

\section{Operation Technique}

Under image intensifier with the patient in supine position with elevation of the shoulder on radiolucent table, open reduction of the acromioclavicular joint was done by downward pressure on the lateral clavicle until it was leveled with the medial end of the acromion, then repair of the capsule with interrupted sutures of AC bond. Finally, the reduced ACJ was transfixed with two K- wires across the joint space. The medial end of the K-wires grasped the cortex of the clavicle; the lateral end was bent to prevent migration.

\section{Postoperative Care}

After surgical stabilization for the first two postoperative weeks an arm to chest bandage was applied, followed by arm sling another 4 weeks. Physiotherapy was started after removal of the arm to chest bandage by active and active assisted movements. Abduction was limited to $70^{\circ}$ until removal of the K-wire.

Six weeks after stabilization, the $\mathrm{k}$-wires were removed. Afterwards the full range of motion was allowed, but heavy lifting, pulling or pushing was forbidden for 3 month. At follow-up each patient was examined in outpatient's clinic. We reported the Constant Score (CS) ${ }^{[17]}$, the clinical stability of the ACJ, the patient's satisfaction, and the serial X-rays findings.

\section{Results}

Patients were followed-up for a period ranged from 8 months to 30 months (Average $18 \mathrm{~m}$ ). The functional outcome was evaluated by the Constant-Murley score ${ }^{[17]}$. The Constant score represents a maximum of 100 points. According to the achieved points the results were grouped into an excellent (> 89 points), good ( $80-89$ points), fair ( $70-79$ points) and poor (< 70 points) outcome. Subjective functional evaluation by the patient in comparison to the contra-lateral shoulder was reported as patient satisfaction. According to Constant score seven patients had excellent score, five good, two fair, and no poor results were obtained.

Complications: Two migrated K-wires five weeks postoperative were removed without influence on the final result. Superficial wound infections occurred in three cases and needed no further surgical treatment, only dressing and oral antibiotic for two weeks. Shoulder stiffness was mild in two cases and did not impair the patient in activities of daily living. No deep infections or nerve palsies.

Radiological evaluation by stress view films to be sure about the reduction and healing of the coracoclavicular and acromioclavicular ligaments revealed good reduction, no ossification were noted, and stable joint with stress view in all patients. All patients returned to previous work after a maximum of one year especially in manual workers.

\section{Discussion}

Early repair of acute ACJ dislocations provides overall good clinical results independent of the surgical method $[1,4,7,18]$. Whereas surgical treatment is recommended for type IV to VI ACJ injuries, the management of type III injuries is still controversial. Depending on the surgical method one has to be aware of complications such as wound infections, osteomyelitis, nerve injuries, ossifications, osteoarthritis, stiffness and breakage or dislocation of screws or wires. For these reasons several authors recommend surgical reconstruction exclusively for young patients, in athletes or for heavy workers ${ }^{[1,19-22]}$ and there is still discussion whether ACJ injuries of type III should be treated conservative or operative. Regarding to the equivalent results of surgical and conservative treatment many authors come to the conclusion that the risks of operation cannot further be accepted $[1,4,12,16$, 19].

For conservative treatment Rawes and Dias stated overall good outcomes at long term follow-up, although all joints were dislocated or subluxed and nearly all patients developed ossifications [23]. They reviewed 30 patients treated conservatively with type III ACJ injury according to Rockwood. All were examined clinically and radiographically, most patients comfort was administered, only one patient with unsatisfactory result.

In contrast, Mouhsine et al. [24] reported poor results of conservative treatment in grad I and II acromioclavicular dislocations. Of 33 patients 9 (27\%) developed chronic ACJ pathology and required further surgery after 26 months. Of the remaining 24,7 complained of activity-related pain, 8 presented residual anteroposterior instability and 12 suffered from tenderness with a mean CS at follow-up of 82 points. Only 17 of the 33 patients $(52 \%)$ remained asymptomatic, only four had no radiographic changes. They concluded that the severity of the consequences after grade I and II AC sprains is underestimated.

Having these poor results of conservative treatment in mind Olaf Rolf et al ${ }^{[25]}$ compared the early and delayed reconstructed ACJ injuries in order to analyze clinical results of the patients which first got conservative treatment after a Rockwood III injury and failed after some time because of persisting instability, pain or weakness. The clinical outcome in the delayed reconstructed group was inferior to the early reconstructed group with a statistically significant difference. Also the delayed reconstructed group suffered more complications and had statistically significant worse results regarding the degree of ACJ reduction in the radiograph at follow-up. Additionally patient's satisfaction was much better in the early reconstructed group. They concluded that the risks of surgical treatment were acceptable and of little influence on the clinical outcome, and they recommended surgical treatment in type III ACJ-injuries immediately after trauma.

It is known from literature that a complete anatomic reduction is not necessary for regaining adequate shoulder function, and that the degree of displacement in type III ACJ dislocations seems not to have a strong influence on the final result $[11,19$, ${ }^{25,26]}$. From this point of view we encouraged to proceed with closed method without open soft tissue repair.

In our study the follow-up period ranged from 8 months to 30 months (Average $18 \mathrm{~m}$ ). Clinically, according to Constant- 
Murley score ${ }^{[17]}$ there were seven patients had excellent score, five good; two fair, and no poor results were obtained. Radiologically stress view films revealed good reduction, no ossification were noted, and stable joint in all patients. We had minor complications without great effect on the final results as: K-wires migration in two patients, superficial wound infections in three cases, and mild shoulder stiffness in two cases. We had no deep infections or nerve palsies.

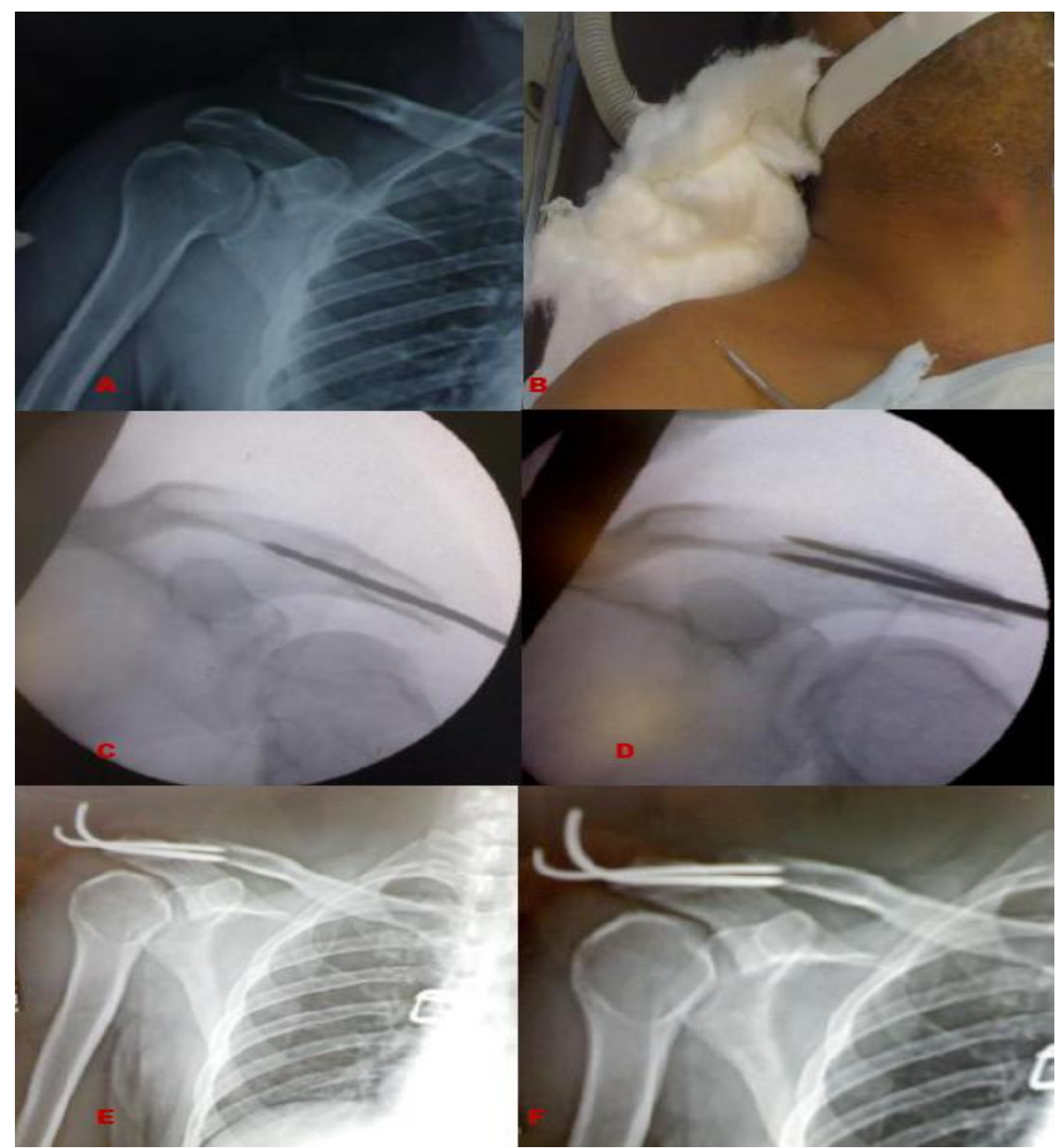

Fig 1: Operative technique: A) Preoperative X-ray; B) Intraoperative positioning of the patient ; C\&D) Intraoperative radiology for K-wire insertion; E) postoperative X-ray; F) X-ray 1 month postoperative.

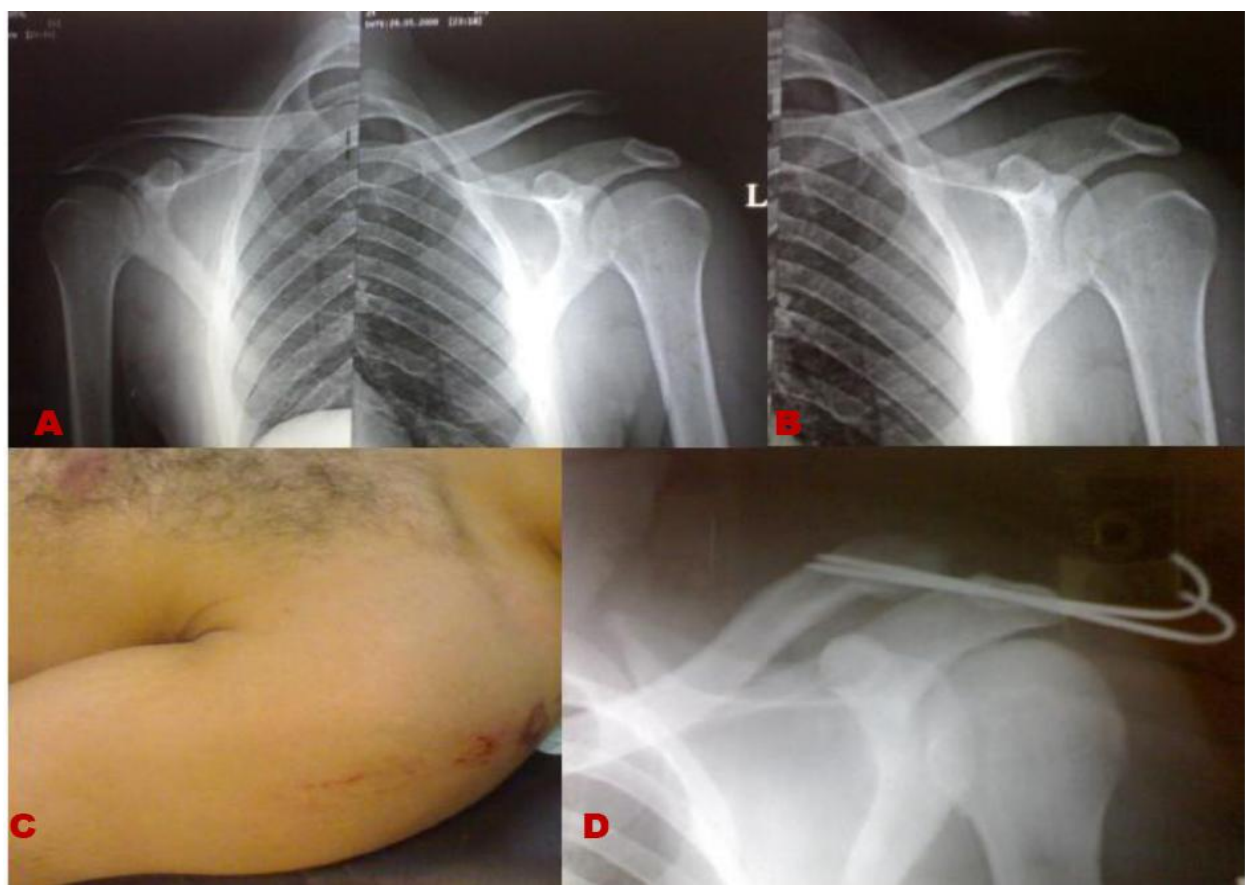




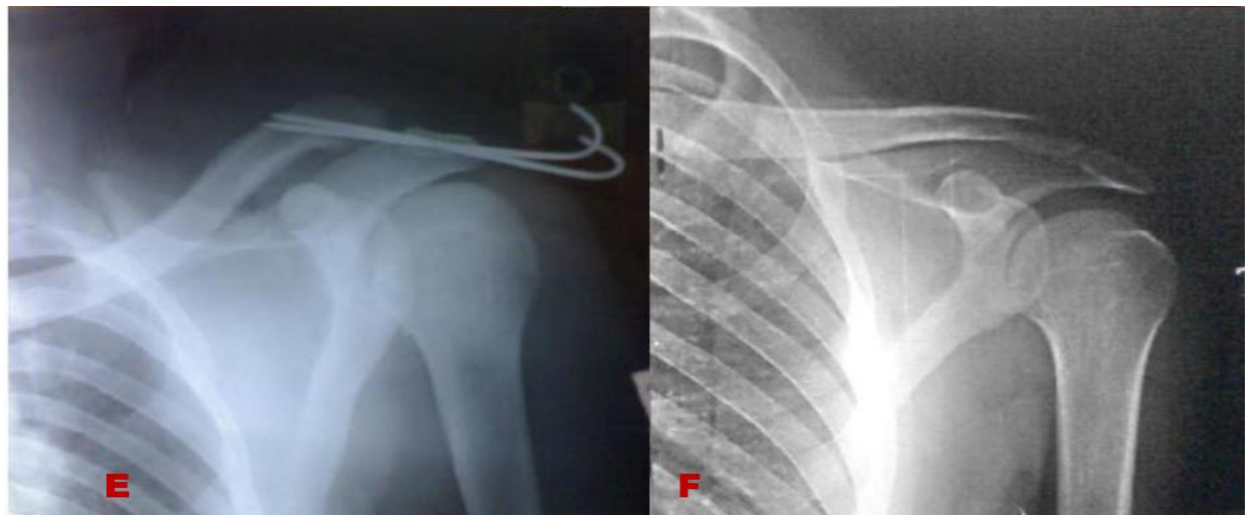

Fig 2: A male patient 34 years old with grade III acromioclavicular dislocation according to Rockwood: A\&B) Preoperative X-ray; C) Intraoperative photo with patient in supine position; D) Postoperative X-ray; E) X-ray 45days postoperative; F) X-ray three months postoperative after removal of $\mathrm{K}$-wires.

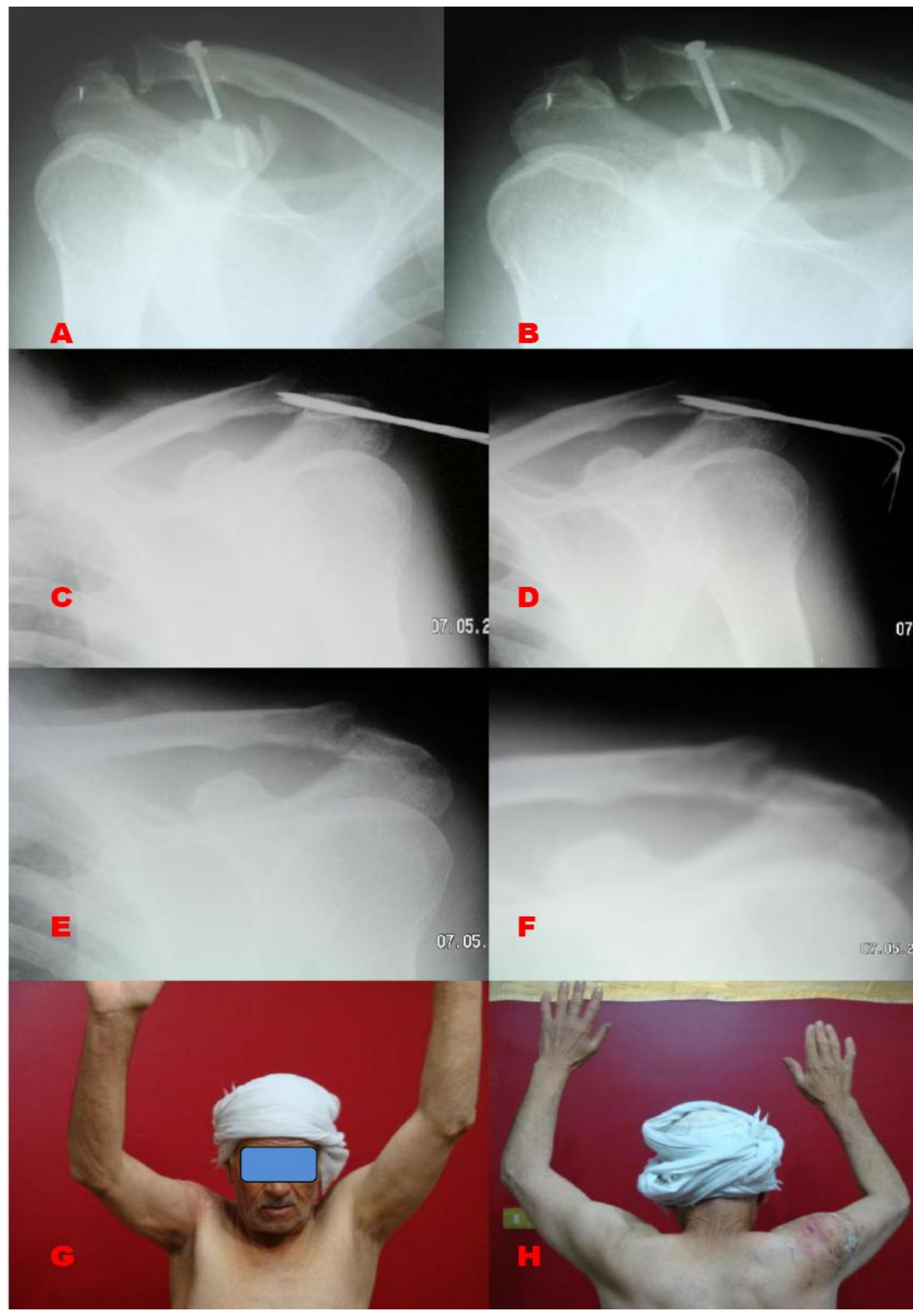

Fig 3: A male patient 60 years old with grade III acromioclavicular dislocation according to Rockwood after coracoclavicular screw implant failure: A\&B) Preoperative X-ray with broken screw; C) Postoperative X-ray; D) X-ray 6weeks postoperative; E) X-ray 1year postoperative; $F \& G)$ Patient photos with full range of movements. 
Table 1: Constant score for clinical shoulder evaluation.

\begin{tabular}{|c|c|c|}
\hline Parameter & Degree & Points \\
\hline & None & 15 \\
Pain & Mild & 10 \\
& Moderate & 5 \\
& Severe & 0 \\
\hline Activities of daily living (Activity level): & Full work & 4 \\
& Full recreation/sport & 4 \\
& Unaffected sleep & 2 \\
\hline Positioning: & Up to waist & 4 \\
& Up to xiphoid & 2 \\
& Up to neck & 6 \\
& Up to top of head & 8 \\
\hline Range of Motion: & Above head & 10 \\
\hline Power (1 point per pound of weight held in abduction by arm at $\left.90^{\circ}\right):$ & Total & 20 \\
\hline \multicolumn{2}{|c|}{} & 40 \\
\hline
\end{tabular}

Table 2: Clinical and radiological results up to the end of the follow up period.

\begin{tabular}{|c|c|c|c|c|c|c|}
\hline \multirow{2}{*}{ parameter } & \multicolumn{2}{c|}{$\begin{array}{c}\text { Postoperative } \\
\text { complications }\end{array}$} & \multicolumn{2}{c|}{ Radiological results } & \multicolumn{2}{c|}{ Clinical Constant score values } \\
\hline \multirow{5}{*}{} & Superficial infection & 3 & Anatomical reduction & 12 & Excellent & 7 \\
\cline { 2 - 7 } & Migrated K-wires & 2 & Subluxation & 2 & Good & 5 \\
\cline { 2 - 7 } & Stiff shoulder & 1 & Redisplacement & 0 & Fair & 2 \\
\cline { 2 - 7 } & No complication & 8 & Breakage of K-wire & 0 & Poor & 14 \\
\hline Total & 14 & 14 & & & 14 \\
\hline
\end{tabular}

\section{Conclusion}

Open reduction, repair of the capsule, and percutaneous transfixing $2 \mathrm{~K}$-wires is a valid and good method for treatment of type III Rockwood acromioclavicular dislocation with little rate of subluxation, joint stiffness, or ligament ossification.

\section{References}

1. Bannister GC, Wallace WA, Stableforth PG, Hutson MA. The management of acute acromioclavicular dislocation. A ran $\neg$ domised prospective controlled trial. J Bone Joint Surg 1989; 71:848-850.

2. Bathis H, Tingart M, Bouillon B, Tiling T. Conservative or surgical therapy of acromioclavicular joint injury: what is reliable? A systematic analysis of the literature using "evidence-based medicine" criteria. Chirurg. 2000; 71:1082-1089.

3. Bradley JP, Elkousy H. Decision making: Operative versus non-operative treatment of acromioclavicular joint injuries. Clin Sports Med. 2003; 22:277-290.

4. Calvo E, Lopez-Franco M, Arribas IM. Clinical and radiologic outcomes of surgical and conservative treatment of type III acromioclavicular joint injury. J Shoulder Elbow Surg. 2006; 15(3):300-305.

5. Rockwood CA Jr, Williams GR, Young DC. Injuries to the Acromioclavicular Joint. In: Rockwood CA Jr, Green DP, Buchholz RW, Heckman JD (eds) Fractures in adults. Lippincott Raven, Philadelphia, 1996, 1341-1413.

6. Weaver JK, Dunn HK. Treatment of acromioclavicular injuries, especially complete acromioclavicular separation. J Bone Joint Surg. 1972; Am 54(6):11871194.

7. Zeiler G. Die: Operative Behandlung der akromioklavikulären Luxation. Operat Orthop Traumato. 1994; 16:38-45.

8. Norell H Jr, Llewllyn RC. Migration of a threaded Steinmann pin from an acromioclavicular joint into the spinal canal: a case report. J Bone Joint Surg. 1965;

\section{A:1024-6.}

9. Nuber GW, Bowen MK. Acromioclavicular joint injuries and distal clavicular fractures. J Am Acad Orthop Surg. 1997; 5:11-8.

10. Phemister DB. Treatment of acromioclavicular dislocation by open reduction and threaded wire fixation. J Bone Joint Surg. 1942; 24:166-8.

11. Phillips AM, Smart C, Groom AF. Acromioclavicular dislocation. Conservative or surgical therapy. Clin Orthop. 1998; 353:10-7.

12. Press J, Zuckermann JD, Gallagher M, Cuomo F. Treatment of grade III acromioclavicular separations: operative versus non-operative management. Bull Hosp Joint Dis. 1997; 56:77-83.

13. Riedl J, Genelin A. Treatment of acromioclavicular dislocations by a pin and tension band fixation. Unfallchirurgie. 1991; 17:140-5.

14. Rockwood CA, Young DC. Disorders of the acromioclavicular joint. In: Rockwood CA, Matsen FA (eds) The shoulder. Saunders, Philadelphia/London 1990, 413-76.

15. Sim E, Schwarz N, Hocker K, Berzlanovich A. Repair of complete acromioclavicular separations using the acromioclavicular hook plate. Clin Orthop. 1995; 314:134-42.

16. Taft TN, Wilson FC, Oglesby JW. Dislocation of the acromioclavicular joint. An end result study. J Bone Joint Surg. 1987; 69A:1045-51.

17. Constant CR, Murley AH. A clinical method of functional assessment of the shoulder. Clin Orthop. 1987; 214:160-4.

18. Lancaster S, Horowitz M, Alonso J. Complete acromioclavicular separations. Clin Orthop. 1987; 216:80-88.

19. Larsen E, Bjerg-Nielsen A, Christensen P. Conservative or surgical treatment of acromioclavicular dislocation: a prospective, controlled, randomized study. J Bone Joint Surg Am. 1986; 68:552-555. 
20. Meislin RJ, Zucherman JD, Nainzadeh N. Type III acromi-oclavicular joint separation associated with late brachial-plexus neurapraxia. J Orthop Trauma. 1992; 6:370-372.

21. Tibone J, Sellers R, Tonino P. Strength testing after thirddegree acromioclavicular dislocations. Am J Sports Med. 1992; 20:328-331.

22. Weaver JK, Dunn HK. Treatment of acromioclavicular injuries, especially complete acromioclavicular separation. J Bone Joint Surg Am. 1972; 54(6):11871194.

23. Rawes ML, Dias JJ. Long-term results of conservative treatment for acromioclavicular dislocation. J Bone Joint Surg Br 1996; 78(3):410-412.

24. Mouhsine E, Garofalo R, Crevoisier X, Farron A. Grade I and II acromioclavicular dislocations: results of conservative treatment. J Shoulder Elbow Surg. 2003; 12(6):599-602.

25. Olaf R, Andreas HW, Alexander E, Thomas DB, Frank G. Acromioclavicular dislocation Rockwood III-V: results of early versus delayed surgical treatment; Arch Orthop Trauma Surg. 2008; 128:1153-1157.

26. Wojtys EM, Nelson G. Conservative treatment of grade III acromioclavicular dislocations. Clin Orthop. 1991; 268:112-119. 